\title{
Working Paper
}

WP No 551

March, 2004

CORPORATE ENTREPRENEURSHIP:

LINKING STRATEGIC ROLES TO MULTIPLE

DIMENSIONS OF PERFORMANCE

Johanna Mair*

Cristina Rata**

* Professor of General Management, IESE

** Post-Doctoral Research Fellow, IESE 


\title{
CORPORATE ENTREPRENEURSHIP: LINKING STRATEGIC ROLES TO MULTIPLE DIMENSIONES OF PERFORMANCE
}

\begin{abstract}
Using data from a large European financial services firm which engaged in an entrepreneurial initiative to enhance its competitiveness, this paper explores the strategic role of middle managers in the context of corporate entrepreneurship and its link to multiple dimensions of performance. The findings indicate that middle managers' role can be decomposed along four reliable and stable dimensions that are consistent with those suggested by the literature. Building on a stakeholder approach, the paper relates the identified roles to multiple dimensions of performance, namely to financial performance, customer satisfaction and employee satisfaction. Canonical correlation analysis $-\mathrm{a}$ useful and powerful method to explore relations among multidimensional variables- indicates a significant but weak relationship.
\end{abstract}

Keywords: corporate entrepreneurship, strategic roles, middle managers 


\section{CORPORATE ENTREPRENEURSHIP: LINKING STRATEGIC ROLES TO MULTIPLE DIMENSIONES OF PERFORMANCE*}

\section{Introduction}

Corporate entrepreneurship (CE) is widely considered as a vital means to stimulate and sustain the overall competitiveness of an organization. Both practitioners and researchers have recognized the challenges of pursuing entrepreneurship within a corporation. CE is the result of the joint activities of an organization's members, activities that pursue strategic objectives and constitute strategic roles. Thus, to face the challenges that CE poses for both theory and practice we need to advance our understanding of the activities and strategic roles involved in the $\mathrm{CE}$ process and their implications for performance. While strategic roles have been extensively studied, most studies analyze the strategic role of top managers and ignore the contribution of middle managers. Moreover, while there is a growing body of empirical evidence of a positive relationship between $\mathrm{CE}$ initiatives and performance, little research emphasizes the contribution of middle managers' strategic roles to superior performance.

It is the intention of this paper to fill this gap by exploring, first, the nature of middle managers' strategic roles in the context of $\mathrm{CE}$, and second, the strategic role-performance relationship. We empirically address these issues by using an exploratory factor analysis to clarify the nature of middle manager's strategic roles and a canonical correlation analysis to link them to multiple dimensions of performance. We base our analysis on data from the retail banking division of a large European financial institution-ABN Amro Bank-which strove to become more entrepreneurial to increase its overall competitiveness. This entrepreneurial initiative, which started in 1997, was a natural reaction to the regulatory, competitive and technological challenges with which European financial services firms, and retail banks in particular, were confronted at the end of the 1990s. To ensure survival and the sustainability of their business, an increasing number of banks, including ABN Amro, explored entrepreneurial approaches to expand their business, renew their structure, and reshape operations (Volberda, Baden-Fuller and van den Bosch, 2001).

Our study makes several contributions to the literature. First, we provide further insights regarding the strategic role of middle managers in stimulating and sustaining corporate entrepreneurship. While previous research has identified various modes of $\mathrm{CE}$ (Covin and Miles, 1999; Dess et al., 2003), we advance current understanding by focusing on two modes of $\mathrm{CE}$ that have been particularly relevant for ABN Amro-sustained regeneration and organizational rejuvenation - and explore the strategic roles that middle managers assume in this context.

\footnotetext{
* This research was (partially) funded through the grant SEC2003-09533 from the Spanish Ministerio de Ciencia y Tecnologia.
} 
Second, we link strategic roles and performance. While most studies have proposed measures that capture only one dimension of performance, we offer a multidimensional measure. Bagozzi and Phillips (1982) and Chakravarthy (1986) have proposed multidimensional performance measures based on financial variables. However, it has been argued that performance measurement based on one-dimensional (financial) measures lacks the necessary diversity to provide managers with the range of information they need for internal management and control (Brancato, 1995). We push forward this line of thinking and apply a stakeholder approach to construct a multidimensional performance measure that takes into account not only financial aspects of performance, but also non-financial aspects, such as customer satisfaction and employee satisfaction.

Finally, we use canonical correlation analysis -an original method- to explore the strategic role-performance relationship. Existing research typically applies either multiple regression analyses -in the case of one-dimensional performance measures- or multi-factor analyses, structural equations models, or cluster analyses -in the case of multiple dimensional measures. The canonical correlation technique is superior, as it takes into account the fact that performance is a multidimensional concept whose underlying dimensions are jointly interacting. It also allows us to construct a performance index by using the weights for the set of performance variables. This technique has been previously employed by Fraser, Phillips and Rose (1974) in their study of the market structure-performance relationship in the banking sector.

The paper is organized as follows. First, we describe the theoretical background of the study. In the following section, we introduce the research setting, describe the data and discuss the measurement. We then explain the analytical techniques used and present the results of the statistical analysis. This is followed by a discussion of the statistical results that includes an interpretation of the middle managers' strategic roles in the context of corporate entrepreneurship, the performance measurement and the performance-strategic roles relationship. We conclude by emphasizing the theoretical contributions, presenting implications for managerial practice and suggesting avenues for further research.

\section{Background}

\section{Middle managers' strategic role in corporate entrepreneurship}

\section{Corporate entrepreneurship}

During the past decade, both researchers and practitioners have perceived CE as an effective approach for revitalizing companies and generating wealth. A review of the literature suggests that $\mathrm{CE}$ may take several forms. For instance, $\mathrm{CE}$ has been viewed as a process -initiated by an individual or a group of individuals pertaining to an organizationthat leads to the creation of a new organization, renewal or innovation within the organization (Sharma and Christman, 1999). It has been associated with a process of strategic renewal (Guth and Ginsberg, 1990) and organizational renewal (Sathe, 1989), as well as a process through which firms carry out diversification (Burgelman, 1983).

While all these forms of CE are considered important, the current study focuses on the conceptualization proposed by Covin and Miles (1999), whose intention was to unify the diverse and sometimes inconsistent definitions of CE. Covin and Miles developed four major modes of $\mathrm{CE}$, which they identified as: sustained regeneration, organizational rejuvenation, 
strategic renewal and domain redefinition. It is important to note that their study illustrates that large diversified corporations may use one or more forms of $\mathrm{CE}$ at the same time.

This study builds on two modes of CE -sustained regeneration and organizational rejuvenation- whose focuses have been previously identified as particularly relevant in the retail banking context (Volberda et al., 2001) and which -as will be argued in the following section- underlie ABN Amro's entrepreneurial initiative.

Sustained regeneration aims at improving a firm's overall competitiveness through corporate strategies that lead to a continuous stream of product/service developments and new market introductions. This requires a combination of proactive and competenceexpanding actions. In organizational rejuvenation, firms seek to sustain or increase competitiveness by improving the effectiveness of existing strategy. This can be achieved by altering a firm's value chain by improving the underlying organizational processes. Some examples include: developing new administrative practices and operating strategies that create value for the corporation's customers or lead to improvements in the firm's ability to successfully implement a strategy, etc.

\section{Middle managers and corporate entrepreneurship}

Bower (1970) was among the first to point to the central role played by middle managers in large diversified firms. Since then, several studies have documented the contribution of middle managers to firms's strategic process (Burgelman, 1983; Kanter, 1982).

Of special interest to our study is the theoretical typology and corresponding measures of middle management roles in strategy developed by Floyd and Woolridge (1992). They identified four dimensions along which middle managers' strategic involvement can be described and measured, namely implementing deliberate strategies, facilitating adaptability, synthesizing information and championing alternatives. Middle managers are involved in championing by presenting alternatives to top management; in synthesizing by interpreting and evaluating information; in facilitating by altering the organizational structure and making it more flexible; and in implementing by aligning organizational activities to top management intentions. For detailed justifications, theoretical support and alternative conceptualizations of these dimensions, see Floyd and Woolridge $(1992,1996)$ and Floyd and Lane (2000).

In the context of corporate entrepreneurship only a few studies have analyzed the strategic contribution of middle management. Burgelman (1985), for example, pointed to the role of middle managers in supporting autonomous strategic initiatives at the operational levels, combining these with the firm's capabilities and developing new strategies. Since strategy is viewed as an essential element for CE (Guth and Ginsberg, 1990; Zahra; 1991), there is a need to understand the role played by middle managers in this context. We want to push forward this line of research by empirically exploring middle managers' strategic roles in the context of $\mathrm{CE}$, seen as a combination of sustained regeneration and organizational rejuvenation. To do so, we built on the typology proposed by Floyd and Woolridge, while taking into account that these typologies may vary with the forms of CE considered.

\section{The relationship with performance}

The literature highlights the importance of CE for improving a company's market and financial performance (Zahra, Nielsen and Bogner, 1999; Wiklund, 1999; Vozikis, 
Bruton, Prasad, D. and Merikas, 1999; Zahra and Covin, 1995; Schollhammer, 1982). The relationship between middle managers' involvement in strategy, on the one hand, and organizational performance, on the other, has been investigated by Floyd and Woolridge (1997). Not much is known, however, about the relationship between middle managers' strategic roles and the multiple dimensions of performance in the context of CE initiatives. It is the purpose of this paper to explore this relationship by adopting a stakeholder approach to assess performance.

\section{A multidimensional approach to measure performance}

Measuring the performance of a firm in general, and of a bank in particular, is a challenging task. Although many studies have analyzed diverse aspects of performance, there is little agreement on how to measure it. Measuring bank subunit performance at the subunit level -probably the most appropriate level to assess outcomes of entrepreneurial initiativesis even more challenging, especially given the difficulty in obtaining data at the subunit level.

The most common measures of performance in bank studies are accountancy-based measures, value-based or market-based measures, and operational measures. Among other more specific criticisms, it has been argued that these measures are inadequate for strategic decision making and planning since they all assume the dominance of the economic and financial goals of a firm 1 . Moreover, these data are particularly difficult to generate at subunit level.

\section{A multidimensional performance measure}

The measures mentioned above have something in common: they all capture only one dimension of performance. Some researchers have argued that performance should be measured along multiple dimensions. Atkinson et al. (1997), for example, claimed that a model for measuring the performance of a firm should take into account the contributions and expectations of all stakeholders of the firm. They further developed such a model and showed how it works in a concrete example involving a bank. According to them, the primary objective of an organization is to maximize the shareholders' wealth (profit). However, to achieve its primary objective, a company must monitor and manage its performance on its secondary objectives, which consist of meeting the needs of the other stakeholders: customers, employees, suppliers and the wider community. This implies that a company must focus on both results and causes and, therefore, that the performance measurement should include both financial and non-financial measures.

This stakeholder approach is supported by many studies in strategic management which emphasize the fact that attention to all relevant stakeholders is a prerequisite for a firm's performance. Traditionally, researchers in different fields of study or disciplines have employed different performance criteria. For example, researchers in finance justify the maximization of shareholder value, as shareholders are the legal owners of the firm (Rappaport 1981), while researchers in marketing require maximization of customer satisfaction because that gives a business focus (Kotler 1991). These approaches try to maximize the welfare of only one stakeholder group, which may result in suboptimal levels of satisfaction for other stakeholders (Chakravarthy, 1986).

1 See McGuire and Schneeweis (1983) and Chakravarthy (1986) for detailed justifications. 
In this study we adopt a stakeholder approach to develop a multidimensional measure of bank subunit performance. Stakeholder theory suggests that organizations consist of various stakeholders and that it is the task of managers to manage the firm in a way that allows the pursuit of multiple objectives. Yet there is little consensus about who is a stakeholder. As a result, stakeholders have been defined in a variety of ways. Freeman (1984) suggested that a stakeholder is a person or group "who can affect or who is affected by the achievement of the organization's objectives". A broad classification of stakeholders would include: stockholders, managers, employees, customers, suppliers and community. Another important issue is the nature of the relationships between the organization and the stakeholders, and among the various stakeholders. It has been argued that these relationships are based on the contributions that the various stakeholders make in return for incentives that the organization provides. For example, employees contribute by performing assigned work, and in return earn a salary and recognition; customers contribute money, and in exchange obtain products and services; and stockholders provide capital and receive monetary benefits (capital gain and dividends). The success of an organization will depend on its ability to integrate and balance the needs of all groups of stakeholders. Therefore, the best way of evaluating the success of an organization is to ascertain and relate the levels of satisfaction it brings to the various stakeholders.

Following this approach, we consider that for an analysis at subunit level the relevant stakeholders are shareholders, employees and customers, and therefore argue that the success (and performance) of a subunit depends on its ability to satisfy all of these groups. Other classifications of stakeholders include suppliers and community as well. However, suppliers would be more appropriate for studies set in manufacturing or non-financial service sectors, and the community is less relevant when analyzing performance at the subunit level.

Given this classification of stakeholders, we decompose the performance measure into three dimensions. One is financial performance, which is intended to capture the satisfaction of the shareholders, and the other two are customer and employee satisfaction.

While the performance measure adopted here is related to the one used by Atkinson et al. (1997), we depart from these authors' work in several ways. First, while Atkinson et al. separated the objectives of an organization into economic (stockholders) and social (customers, employees, community) objectives, the latter being secondary, we integrate the two objectives and focus on the system as a whole, leaving the task of deciding the importance of each to statistical analysis. Second, we analyze the performance of a bank at subunit level, while they examined overall bank performance. The direct implications of these choices are that we (1) do not include the community as a group of stakeholders, (2) use a different measure for financial performance, and (3) support our findings by providing an empirical investigation of the issues.

Our approach is also supported by the practical implications of several articles. For example, Eccles (1991) mentioned a senior executive at one large bank who proposed new measures such as customer satisfaction, customers' perceptions of the bank's stature and professionalism, and market share, to serve as indicators of performance. Also, a case study from Skandia Life ${ }^{2}$, a company providing financial services, revealed that this company has used employee satisfaction, customer service and financial objectives as key measures of company performance.

2 This case study was published in Strategic Communication Management, June/July, 1997, under the title "Employee Satisfaction as a Measure of Organizational Performance: A Case Study from Skandia Life". 


\section{Research methods}

We relied on objective and subjective sources to gather data. We used company archives to collect performance and satisfaction data, and self-reported data to assess middle managers' activities that constitute strategic roles in the context of CE. In what follows we first provide the reasons for the selection of ABN Amro for the purpose of this analysis, and then describe the data sources and measurement.

\section{Research setting}

Faced with increasingly demanding customers, intensified competition from abroad and non-financial institutions, together with new and cheaper methods of distribution, in 1997 ABN Amro -a large Dutch financial services company- launched Vision 2000, a project to foster entrepreneurial initiative in order to increase its competitiveness in the domestic market. ABN Amro reshuffled its operations in the Netherlands, split the domestic market into 207 micro markets, and appointed a middle manager for each of these newly created independent units (areas). These 207 units and the role played by the middle managers in charge of them are at the center of this study.

ABN Amro was historically organized according to hierarchical -almost bureaucratic- principles. This "administrative heritage" (Bartlett and Ghoshal, 1989) limited considerably the involvement of managers in strategy. Several hierarchical layers supported centralized decision-making processes and largely inhibited autonomous behavior on the frontline. Besides structural factors discouraging proactive behavior, the very nature of the business -domestic retail banking- also failed to provide incentives for entrepreneurship in the classical sense. The market for domestic commercial banking in the Netherlands was mature and the product portfolio relatively fixed. Limited room thus existed for innovation related to new product or technology development, or for expanding the boundaries of market space (Kim and Mauborgne, 1999).

In sum, an organizational structure based on hierarchical principles, combined with the risk-averse nature of retail banking, nurtured a behavioral context and culture based on reactive rather than proactive behavior. Major emphasis was given to compliance with rules, which included asking for permission before engaging in any form of non-routine behavior. In other words, executing orders rather than taking initiative was the dominant behavioral pattern of employees at the middle management level.

\section{Vision 2000}

Vision 2000 was about changing these traditional patterns of behavior that had become "institutionalized" at ABN Amro over time. While the project, at first glance, appeared to be about restructuring and decentralization, the splitting up of the domestic market into 207 autonomous micro-markets and the shifting of authority were merely a means to the end of fostering entrepreneurial initiative, which itself was seen as the means to achieve the ultimate long-term goal of improving overall competitiveness by creating value for the bank's customers and winning back market share from the competitors.

Vision 2000 envisioned a more entrepreneurial culture by encouraging proactive and results-oriented behavior on the part of managers, which in turn would lead to an increase in customer satisfaction. Furthermore, it aimed to make the bank more innovative by fostering a 
more flexible internal structure and new systems and capabilities that would lead to a rapid development of the new products and services demanded by the market. In sum, Vision 2000 represented a $\mathrm{CE}$ initiative that clearly aimed at sustained regeneration and organizational rejuvenation.

\section{Data}

The data collection process included two phases. In a first step we conducted forty semi-structured interviews (with middle managers, their bosses and subordinates) to explore the nature of the activities that constitute the strategic roles of the middle managers in the context of CE. More precisely, we first interviewed the originators and implementers of Vision 2000 at headquarters. To identify key patterns and issues, we then conducted exploratory unstructured interviews with area managers responsible for units of varying size and customer structure. In addition, we gathered interview data from experts inside and outside the bank and triangulated findings. Finally, to investigate underlying mechanisms and to corroborate initial patterns, we carried out an additional round of semi-structured interviews with area managers, their supervisors and occasionally their subordinates. It was this third round of interviews that provided the necessary input for developing items. To add discriminative power, we sampled area managers on performance and region. Comparing qualitative observations across performance levels and regions allowed us to identify activities constituting strategic roles. In addition, triangulation of interview data from area managers, their subordinates and their bosses, as well as our own personal observations, allowed us to compare action profiles and to control for biases stemming from the nature of self-reported data.

Questionnaires were sent to middle managers of 205 areas. Responses were received from 150 managers (72 per cent response rate). The middle managers represented in this sample covered all the regions of the Netherlands. To evaluate non-response biases we compared regional distribution, size, and performance of the units in the "returned" sample with the ones in the "not-returned" sample. No significant differences were found. As suggested by the relevant literature, we eliminated social desirability effects as far as possible by clarifying introductions and accurate phrasing of questions (Rossi, Wright, and Anderson, 1983).

To follow performance over time (1997 until the end of 1999) and to ensure comparability, we included only those middle managers who assumed their job with the launch of the entrepreneurial project at ABN Amro at the beginning of 1997.

One area was eliminated (the national airport, Schipol) because of its particularities with respect to both business and inhabitants and, subsequently, financial performance and customer satisfaction. For another area no financial performance data were available. The final sample included 119 middle managers.

\section{Measurement}

\section{Financial performance}

Return on assets (ROA) and return on equity (ROE) are among the most frequently used financial indicators in banking studies. Among other more specific criticisms (White et al., 1997; Chakravarthy, 1986), it has been argued that these measures are not appropriate for analysis at subunit level due to the problems associated with the distribution of assets and equity to particular subunits. 
We measured financial performance by income growth, where the growth dimension was captured by an index comparing the results of 1997 with those of the end of 1999 $(1997=100)$. Net income and net income growth have been employed in several studies (Child, 2001; (Grinyer et al., 1988; Venkatraman and Ramanujam, 1986; Wood and LaForge, 1979 - for banks).

\section{Customer satisfaction}

Development in customer satisfaction was measured by an index that captured the growth in customer satisfaction in the time period 1997-1999 (1999=100). Within ABN Amro, customer satisfaction at the area level is assessed on an annual basis. Accounts of customer satisfaction report the percentage of very satisfied customers, i.e., those customers who indicate a satisfaction level of 8 or more (on a scale from 1-10). The reported level of satisfaction refers to retail customers.

\section{Employee satisfaction}

Like customer satisfaction, subordinate satisfaction within ABN Amro is assessed at the area level via surveys conducted on an annual basis. Survey questions include employees' satisfaction regarding their particular jobs, remuneration, support, and ABN Amro as a workplace in general. Accounts of subordinate satisfaction report the percentage of satisfied employees, i.e., those employees who answered positively and indicated their level of satisfaction with a score of 1 or 2 on a scale ranging from 1 (total agreement) to 5 (total disagreement).

\section{Strategic roles}

As described in the previous subsection, a context-specific instrument to measure the activities constituting strategic roles was developed. The instrument includes questions about the extent to which area managers engaged in particular activities. The questionnaire used a 7-point Likert-scale with $1=$ No Extent and $7=$ To a Great Extent (see Appendix 1). The items constituting the final scale of strategic roles are derived in the next section.

\section{Analysis and results}

\section{Model estimation procedures}

To empirically explore the nature of strategic roles in the context of $\mathrm{CE}$ and the implications for performance, we proceeded as follows. First, we conducted an exploratory factor analysis, using principal components extraction and varimax rotation, to find the underlying structure of the set of strategic role variables. We then used canonical correlation analysis to explore the relationship between the multiple dimensions of performance and the set of strategic roles identified in the first step. Both analyses were carried out in SPSS.

While factorial analysis is an estimation technique that is used very often and does not need much explanation, canonical correlation has been seldom employed and therefore calls for a short explanation. 
Canonical correlation analysis is an exploratory, dimensionality-reducing technique that is also predictive. In particular, it provides answers to questions concerning: (a) the existence of one or more relationships between two sets of variables, (b) the strength(s) of the relationship(s), and (c) the nature of the relationships defined. Given these features, we believe canonical correlation to be the right estimation tool for the purpose at hand.

Canonical correlation studies the relationship (intercorrelational structure) between two sets of variables: the set of dependent (criterion) variables and the set of independent (predictor) variables. In our case, the set of criterion variables is given by the measures of the bank's performance, and the set of predictor variables consists of the principal components from the factor analysis. The relationship, and the main hypothesis, can be written as:

$$
\mathrm{Y}=\mathrm{f}(\mathrm{X})
$$

where, $\mathrm{Y}$ is the vector of criterion variables and $\mathrm{X}$ is the vector of predictor variables, which is expected to influence $\mathrm{Y}$.

The model replaces the two sets of variables by one or more linear combinations of the variables in each set. The canonical correlation is the maximal correlation between these linear combinations.

Canonical correlation is very useful in our context because it takes into account the fact that performance is a multidimensional concept whose underlying dimensions are potentially related, and it allows us to construct a performance index. Also, canonical correlation analysis is particularly appropriate when there is a possible series of multiple regressions on data that explain a series of variables that are potentially related. Many studies on performance that relied mainly on multiple regressions indicated various relationships among the performance variables proposed here, suggesting that more research is needed to generate a holistic understanding of the performance concept. For example, while Faulhaber (1995) found that greater consumer satisfaction correlates with greater profitability, Frei et al. (1999) noticed that better performing banks do not necessarily have better customer satisfaction. Many empirical results are subject to the usual discussion of causality versus association. While Heskett et al. (1994) considered employee and customer satisfaction as links in a chain that lead to greater profit, other authors regarded them as measures of performance (Fornell et al., 1996).

In sum, we argue that canonical correlation is a valuable tool in performance research as it involves a clear distinction between independent and dependent variables, multiple dependent variables, and the potential for multidimensional relations between these two sets of variables.

We are aware of two articles, Mahmood et al. (1993) and Fraser et al. (1974), which have applied the canonical correlation technique in a multidimensional performance context. However, these studies analyzed different issues than the ones proposed here. Specifically, Mahmood et al. looked at the relationship between organizational strategic and economic performance measures and information technology investment measures, while Fraser et al. considered the relationship between performance and market structure for banking services.

Finally, factor analysis and canonical correlation are members of the multiple general linear hypothesis family and share many of the assumptions of multiple regression models, such as linearity ${ }^{3}$ of relationships, homoskedasticity, interval or near-interval data,

3 Canonical correlation requires that the independents and dependents be linear among themselves. 
lack of high multicollinearity, and multivariate normality for purposes of hypothesis testing. Our data satisfy these assumptions ${ }^{4}$.

\section{Results}

\section{Factor analysis}

Factor analysis ${ }^{5}$ was run with the 22 items capturing entrepreneurial activities and measuring the diverse aspects of middle managers' strategic roles in the context of CE. The Kaiser measure of sampling adequacy of 0.801 indicates that the data are adequate 6 for the factor analysis.

To determine the number of factors, we used the Kaiser rule - one of the most common rules of thumb for dropping the least important factors from the analysis. The Kaiser rule is to remove all components with eigenvalues under 1.0. As Table 1 suggests, we have isolated six factors, representing different strategic roles. Appendix 2 provides the description of the items loading on each factor.

Table 1. Factor analysis results

\begin{tabular}{|c|c|c|c|c|c|c|}
\hline $\begin{array}{l}\text { Factor } \\
\text { (var. expl) }\end{array}$ & $\begin{array}{c}\text { Strategic role } 1 \\
(9.1 \%)\end{array}$ & $\begin{array}{c}\text { Strategic role } 2 \\
(27.2 \%)\end{array}$ & $\begin{array}{c}\text { Strategic role } 3 \\
(6.2 \%)\end{array}$ & $\begin{array}{c}\text { Strategic role } 4 \\
(7.9 \%)\end{array}$ & $\begin{array}{c}\text { Strategic role } 5 \\
(5.3 \%)\end{array}$ & $\begin{array}{c}\text { Strategic role } 6 \\
(6.1 \%)\end{array}$ \\
\hline \multicolumn{7}{|l|}{ Item } \\
\hline Item 1 & 0.72 & & & & & \\
\hline Item 2 & 0.66 & & & & & \\
\hline Item 3 & 0.79 & & & & & \\
\hline Item 1 & & 0.71 & & & & \\
\hline Item 2 & & 0.75 & & & & \\
\hline Item 3 & & 0.81 & & & & \\
\hline Item 4 & & 0.70 & & & & \\
\hline Item 1 & & & 0.78 & & & \\
\hline Item 2 & & & 0.77 & & & \\
\hline Item 3 & & & 0.60 & & & \\
\hline Item 4 & & & 0.42 & & & \\
\hline Item 1 & & & & 0.44 & & \\
\hline Item 2 & & & & 0.54 & & \\
\hline Item 3 & & & & 0.76 & & \\
\hline Item 4 & & & & 0.49 & & \\
\hline Item 5 & & & & 0.52 & & \\
\hline Item 1 & & & & & 0.69 & \\
\hline Item 2 & & & & & 0.62 & \\
\hline Item 3 & & & & & 0.68 & \\
\hline Item 1 & & & & & & 0.70 \\
\hline Item 2 & & & & & & 0.64 \\
\hline Item 3 & & & & & & 0.65 \\
\hline
\end{tabular}

Note: Kaiser-Meyer-Oklin Measure of Sampling Adequacy $=0.80$.

4 We tested normality of the variables. Since multivariate normality is not a critical assumption in canonical analysis, we believe this to be satisfactory.

5 To decide whether the size of our sample is adequate for an exploratory factor analysis, we used the STV ratio rule proposed by Bryant and Yarod (1995). This rule requires the cases-to-variables ratio to be at least 5 , which is the case in our analysis.

6 A value of 0.60 for Kaiser's measure of significance adequacy is significant. 
With very few exceptions, all items had loadings ${ }^{7}$ of at least 0.60 , suggesting that we were successful in isolating the above constructs.

To assess the reliability of the constructs, Cronbach's Alpha and corrected item-total coefficients were computed (see Table 2). A common rule of thumb is that the items should have a Cronbach's Alpha of .7 to provide confidence that the individual items are consistent and reliable. As Table 2 shows, only four constructs are satisfactory, namely Strategic role 1, Strategic role 2, Strategic role 3, and Strategic role 4. Most item-total correlation coefficients for these constructs were above 0.50 , indicating that most items share a high degree of variance with their respective constructs. Reliability is necessary for measurement to be valid, but not sufficient. Validity assessment involves demonstrating that the item(s) is actually measuring the theoretical construct supposedly measured by the item(s). Unidimensionality and discriminant validity were used to evaluate validity. Unidimensionality assumes constructs to measure a single dimension of meaning. To assess unidimensionality, Armor's (1974) theta was computed. All constructs satisfied the unidimensionality requirement. Discriminant validity refers to the principle that the items for different constructs should not be so highly correlated as to lead one to conclude that they measure the same thing. Discriminant validity was evaluated for all construct pairs by examining the observed correlation matrix of the underlying items. A common rule of thumb is to use a correlation of 0.85 as a cutoff for this assessment. Correlation ranged from 0.03 to 0.54 , meaning that all construct pairs meet the discriminant validity condition.

Table 2. Descriptive statistics and measurement reliability

\begin{tabular}{|c|c|c|c|c|}
\hline Scale & Mean & $\begin{array}{l}\text { Standard } \\
\text { Deviation }\end{array}$ & Alpha & $\begin{array}{l}\text { Correlated } \\
\text { Item-total } \\
\text { Correlation }\end{array}$ \\
\hline STRATEGIC ROLE 1 & 5.25 & 0.953 & 0.70 & \\
\hline Item 1 & 5.75 & 1.043 & & 0.55 \\
\hline Item 2 & 5.02 & 1.328 & & 0.55 \\
\hline Item 3 & 4.98 & 1.221 & & 0.49 \\
\hline STRATEGIC ROLE 2 & 3.65 & 1.090 & 0.78 & \\
\hline Item 1 & 3.94 & 1.475 & & 0.52 \\
\hline Item 2 & 3.96 & 1.291 & & 0.55 \\
\hline Item 3 & 3.55 & 1.424 & & 0.65 \\
\hline Item 4 & 3.16 & 1.444 & & 0.60 \\
\hline STRATEGIC ROLE 3 & 4.70 & 0.987 & 0.74 & \\
\hline Item 1 & 4.22 & 1.451 & & 0.55 \\
\hline Item 2 & 5.07 & 1.198 & & 0.48 \\
\hline Item 3 & 4.61 & 1.341 & & 0.56 \\
\hline Item 4 & 4.88 & 1.283 & & 0.53 \\
\hline STRATEGIC ROLE 4 & 4.38 & 0.999 & 0.69 & 0.432 \\
\hline Item 1 & 4.87 & 1.207 & & 0.49 \\
\hline Item 2 & 4.79 & 1.192 & & 0.52 \\
\hline Item 3 & 3.42 & 1.654 & & 0.38 \\
\hline Item 4 & 4.55 & 1.539 & & 0.46 \\
\hline Item 5 & 4.28 & 1.775 & & \\
\hline
\end{tabular}

7 Common social science practice uses a minimum cut-off of .3 or .35 . An arbitrary rule-of-thumb considers loadings as "weak" if less than .4 , "strong" if more than .6, and otherwise as "moderate". 
Table 2 (continued)

\begin{tabular}{lllll} 
STRATEGIC ROLE $\mathbf{5}$ & $\mathbf{4 . 6 1}$ & $\mathbf{1 . 0 0 8}$ & $\mathbf{0 . 5 9}$ & \\
Item 1 & 5.15 & 1.212 & & 0.39 \\
Item 2 & 5.03 & 1.245 & & 0.45 \\
Item 3 & 3.65 & 1.587 & & 0.37 \\
& & & & \\
STRATEGIC ROLE $\mathbf{6}$ & $\mathbf{3 . 8 5}$ & $\mathbf{1 . 0 9 6}$ & $\mathbf{0 . 6 2}$ & 0.42 \\
Item 1 & 5.23 & 1.238 & & 0.41 \\
Item 2 & 1.88 & 1.433 & & 0.47 \\
Item 3 & 3.45 & 1.666 & & \\
\hline
\end{tabular}

Given their satisfactory statistical properties, strategic roles 1-4 were used for further analysis. Strategic role 1 described middle managers' task of leading and guiding their employees in an entrepreneurial manner. This typically implies empowering and encouraging employees to be proactive. In this role the middle manager acts as a "leader" who stimulates entrepreneurship across hierarchical levels. Strategic role 2 mirrors the middle manager's role as a "broker". By linking and sharing, the middle manager facilitates the flow of know-how between business units (areas); exchanges ideas with sparring-partners in and outside the organization; transmits and takes up best practice; and establishes an informal network both within the organization and with the outside world. Strategic role 3 resembles the "businessman" role of middle managers and involves their efforts to identify and pursue innovative ways to do business, systematically pursue market opportunities and build a face in the market. Finally, strategic role 4 corresponds to middle managers' role as "architects", which consists of their efforts to renew and reorganize structure and processes in their units to enable entrepreneurship at all levels.

In the next section, the four strategic roles identified here will be related to sustained regeneration and organizational rejuvenation, the modes of $\mathrm{CE}$ introduced by Covin and Miles (1999), as well as to Floyd and Woolridge's (1992) typology of strategic roles discussed previously.

To proceed with the analysis we created four scales by taking the average of the underlying items. The correlations among the scales are displayed in Table 3 . They are all positive and significant.

Table 3. Correlations for the consturcts underlying the set of entrepreneurial activity variables

\begin{tabular}{|l|l|l|l|l|l|}
\hline Scale & $\mathbf{1}$ & $\mathbf{2}$ & $\mathbf{3}$ & $\mathbf{4}$ & $\mathbf{5}$ \\
\hline 1 STRATEGIC ROLE 1 & & & & & \\
2 STRATEGIC ROLE 2 & $0.25^{* *}$ & & & & \\
3 STRATEGIC ROLE 3 & $0.36^{* *}$ & $0.34 * *$ & & & \\
4 STRATEGIC ROLE 4 & $0.48^{* *}$ & $0.32 * *$ & $0.54 * *$ & & \\
5 STRATEGIC ROLE 5 & $0.24 * *$ & $0.19 *$ & $0.35^{* *}$ & $0.39 * *$ & \\
6 STRATEGIC ROLE 6 & $0.29^{* *}$ & $0.31^{* *}$ & $0.45^{* *}$ & $0.45^{* *}$ & $0.39 * *$ \\
\hline
\end{tabular}




\section{Canonical correlation analysis}

Given the four relevant strategic roles obtained above, canonical correlation ${ }^{8}$ was performed to evaluate the performance-strategic roles relationship. The main hypothesis becomes:

$\left(Y_{1}, Y_{2}, Y_{3}\right)=f\left(X_{1}, X_{2}, X_{3}, X_{4}\right)$

where:

Performance dimensions:

$Y_{1}=$ financial performance

$Y_{2}=$ customer satisfaction

$Y_{3}=$ employee satisfaction

Strategic role dimensions:

$X_{\mathrm{i}}=$ strategic role $i$, for $i=\{1,2,3,4\}$

The canonical correlation output is summarized in Figure 1.

Figure 1. Canonical correlation results

\begin{tabular}{|c|c|c|c|c|c|c|}
\hline \multicolumn{3}{|c|}{ STRATEGIC ROLES } & \multirow[b]{2}{*}{$R=.29(<.05)$} & \multicolumn{3}{|c|}{ STRATEGIC ROLES } \\
\hline & $\begin{array}{c}\text { Canonical } \\
\text { loadings } \\
\end{array}$ & $\begin{array}{l}\% \text { variance } \\
\text { explained }\end{array}$ & & & $\begin{array}{c}\text { Canonical } \\
\text { loadings } \\
\end{array}$ & $\begin{array}{l}\% \text { variance } \\
\text { explained }\end{array}$ \\
\hline $\begin{array}{l}\text { - Role } 1 \text { Leader } \\
\text { - Role } 2 \text { Broker } \\
\text { - Role } 3 \text { Businessman } \\
\text { - Role } 4 \text { Architect }\end{array}$ & $\begin{array}{l}.30 \\
.34 \\
.07 \\
.86\end{array}$ & $\begin{array}{r}9.27 \\
14.27 \\
0.25 \\
76.21\end{array}$ & $\underset{5.1 \%}{\text { Redundancy }}$ & $\begin{array}{l}\text { - Financial performance } \\
\text { - Customer satisfaction } \\
\text { - Employee satisfaction }\end{array}$ & $\begin{array}{l}.56 \\
.60 \\
.64\end{array}$ & $\begin{array}{l}28.95 \\
33.23 \\
37.82\end{array}$ \\
\hline $\begin{array}{l}\text { Proportion of va } \\
\text { its own canor }\end{array}$ & $\begin{array}{l}\text { nnce explai } \\
\text { al variate: }\end{array}$ & & & $\begin{array}{l}\text { Proportion of var } \\
\text { its own canoni }\end{array}$ & $\begin{array}{l}\text { lance explail } \\
\text { cal variate: } 2\end{array}$ & $\frac{d}{d}$ by \\
\hline
\end{tabular}

The canonical correlation is a form of correlation relating the two sets of variables. There may be more than one canonical correlation, each representing an orthogonally separate pattern of relationships between the two sets of variables. However, it is the first canonical correlation that explains most of the relationship. Its square is the percent of variance in the dependent canonical variable (the linear combination of variables in a set) explained by the independent canonical variable. The significance of the canonical correlation may be tested using Wilk's lambda. The canonical correlation analysis revealed only one significant $(\mathrm{p}<0.05)$ canonical correlation of .293 (8.58\% overlapping variance), which can be interpreted as evidence that there is an association between the strategic roles

8 Canonical correlation was performed using the CANCORR program of SPSS.

9 The redundancy index for a set of variables is the product of the average of the squared structural correlations of the variables in the set and the squared canonical correlation. Therefore, there are two redundancy indexes, one for the set of criterion variables - giving the proportion of variance of this set explained by the opposite canonical variate - and the other for the set of predictor variables. The final redundancy index is the sum of these two redundancy indexes. 
and performance variables. In particular, the strategic (independent) canonical variable explains $8.58 \%$ of the variance in the performance canonical variable.

However, assuming a statistically significant canonical correlation, the amount of relationship can be determined using a redundancy index. Whereas the canonical correlation measures the strength of association between the two sets of variables, the redundancy index indicates the magnitude of relationship, i.e., the effectiveness of all canonical variates in the solution in capturing the variance of the original variables, thus providing information about the practical significance of the canonical functions. The redundancy index was computed using the measure proposed by Stewart and Love (1968). The redundancy index ${ }^{9}$ is .051 , meaning that the two sets of variables share $5.1 \%$ of their variance. This suggests a weak multivariate relationship between the strategic dimensions and performance. One can provide additional redundancy analysis of how well each canonical variate predicts values of its original variables. In our case, the strategic (independent) canonical variable is able to predict $36 \%$ of the variance in the individual original independent variables, and the dependent performance canonical variable is able to predict $24 \%$ of the variance in the individual original dependent variables. These results suggest that both the independent and dependent variates account for a relatively high percent of the variance in their corresponding sets of original variables.

In order to interpret the results, factor loadings (or structure correlations) were used (Levine, 1977; Meredith, 1964; Thorndike and Weiss, 1973) ${ }^{10}$. The factor loadings show how the original variables load on the canonical correlation variable. Their magnitudes help in interpreting the meaning of the canonical variables with which they are associated. A rule of thumb is for variables with structure correlations of .30 or above to be interpreted as being part of the canonical variable. In our case, all the variables, except Strategic role 3 (businessman), can be considered as part of the corresponding canonical variable. Also, the magnitude of the structure correlations suggests that the independent canonical variable is most related to strategic role 4 (architect), whereas the dependent canonical variable is almost equally related to all the underlying variables. Further, both dependent and independent canonical variables are positively related to the original variables, confirming our expectations. Finally, an examination of the canonical loadings in the independent set suggests that the most important influence on performance is strategic role 4 (architect), affecting performance positively.

\section{Discussion}

\section{Conceptualizing managers' strategic roles in the context of organizational rejuvenation and sustained regeneration}

As already suggested by Dess et al. (2003), middle managers' strategic roles in the context of sustained regeneration and organizational rejuvenation include, but are not limited to, two dimensions: implementing, and synthesizing and facilitating. Championing, the only

10 These authors have argued that canonical correlation output should be interpreted using factor loadings rather than canonical weights. The canonical weights, which are generalized regression weights, are difficult to interpret because they may be greater than 1 and the correlation among the observed variables may affect the weights. Another criticism is that regression weights tend to have larger standard errors, and thus be less stable than correlations. Levine argued against the use of regression weights on the ground that the canonical coefficients may be subject to multicollinearity, leading to incorrect judgments. Using the structure correlations for interpretation reasons is now the standard approach. 
dimension left aside, is considered as an essential element in the middle management strategy in the context of strategic renewal and domain redefinition rather than for the $\mathrm{CE}$ forms considered here (Dess et al., 2003).

Similar findings are sustained by the factorial analysis in section 4. More precisely, our results suggest that middle managers' strategic roles can be decomposed along four dimensions. While Dess et al. (1999) saw synthesizing and facilitating as one dimension of the strategic roles in the context of sustained regeneration and organizational rejuvenation, our results hint at separate roles for middle managers in synthesizing in the context of sustained regeneration and facilitating in the context of organizational rejuvenation. Our findings are summarized in the following matrix.

\section{Corporate entrepreneurship mode}

\begin{tabular}{l|c|c|c|}
\multicolumn{2}{c}{} & \multicolumn{1}{c}{$\begin{array}{c}\text { Sustained } \\
\text { regeneration }\end{array}$} & \multicolumn{1}{c|}{$\begin{array}{c}\text { Organizational } \\
\text { rejuvenation }\end{array}$} \\
\cline { 2 - 4 } $\begin{array}{l}\text { Strategic } \\
\text { role of middle } \\
\text { managers }\end{array}$ & Implementing & Businessman & Architect \\
Synthesizing & Leader & Broker \\
\hline Facilitating & & \\
\hline & & & \\
\hline & & & \\
\hline
\end{tabular}

Implementing in the context of sustained regeneration - Strategic role 3 "Businessman"

Implementation entails middle management's involvement in corporate strategies of continual product/service development or new market introductions while being coherent with top management intentions. This requires proactive actions that lead to the identification of new market opportunities, taking initiatives that expand the business of the company, and motivating change by supporting employees in developing new ideas. In their role as businessmen, middle managers apply entrepreneurial approaches to implement strategy developed at the top aimed at building and sustaining a market presence and thus enhancing the overall competitiveness of the firm.

\section{Implementing in the context of organizational rejuvenation - Strategic role 4 "Architect"}

Implementation involves middle management contribution to sustaining or improving the effectiveness of existing business strategies while remaining coherent with the top management's goals. This can be done by introducing new administrative techniques that facilitate the implementation of a formal strategy, reorganizing processes and introducing new services to create value for customers, and motivating change by promoting entrepreneurial behavior by employees. As an architect, the middle manager focuses on structure, systems and processes and aims at creating a "framework for action", which includes modifying the physical set-up of the unit, installing new processes and procedures, creating and realigning functions and services within the business unit, and setting up new communication forums. 
Synthesizing in the context of sustained regeneration - Strategic role 1 "Leader"

Synthesizing entails middle management involvement in corporate strategies to improve organizational arrangements by framing ideas and selling issues. This can be done by promoting initiative taking among employees, as well as employee involvement in decision making, with the end purpose of developing rapid decision-making capabilities and a flexible organizational structure. As a leader, the middle manger involves employees in idea generation and decision making, motivates and stimulates, tries to get the best out of everybody, and influences attitudes and behavior in a subtle manner. The main focus is on people, i.e. employees within the area, and on creating a supportive working environment. Creating an atmosphere of trust is seen as an important means to diffuse the entrepreneurial spirit and encourage employees at all levels to act entrepreneurial.

\section{Facilitating in the context of organizational rejuvenation - Strategic role 2 "Broker"}

Facilitating requires a middle management contribution to sustaining or improving the effectiveness of existing business strategies by contributing to and encouraging organizational learning. This can be done by freely sharing information and encouraging people to try new things. The middle manager as a broker actively facilitates the flow of know-how between business units (areas); exchanges ideas with sparring-partners in and outside the organization; transmits and takes up best practice; and establishes an informal network both within the organization and with the outside world.

\section{Multidimensional conceptualization of performance}

While most studies that have pointed to the need for multidimensional conceptualizations of performance have considered only indicators of financial performance, some have proposed measures based on both non-financial and financial measures. However, even among the latter (Atkinson et al., 1997; Dess et al., 2003), no specific empirical support on the underlying dimensions of the performance was provided. Our study has used a stakeholder approach to offer a multidimensional conceptualization of performance and has proposed a novel multivariate technique to empirically test it.

The canonical loadings of the dimensions underlying the performance measure suggest a positive and nearly even contribution of financial performance, customer satisfaction and employee satisfaction to the performance measurement. Employee satisfaction and customer satisfaction, however, exhibit slightly higher loadings than financial performance, emphasizing their importance for performance. Employee satisfaction, with a loading of .638 , appears to be the most important dimension of performance. Customer satisfaction is the second most important dimension of performance, with a loading of .600 . Financial performance is ranked third, with a load of .564. These findings support the argument that human and customer capital are assuming increasing importance for firm performance (Nahapiet and Ghoshal, 1998; Fornell et al., 1996).

Further, the loadings derived from the canonical correlation analysis can be used as weights to construct a weighted multivariate measure of performance. While some attempts have already been made in this direction (Altman, 1971; Fraser et al. 1974), we are not aware of any empirical study that uses both non-financial and financial indices to construct such an index. 
In conclusion, our findings suggest that performance is a multidimensional concept, consisting of several measures that jointly interact.

\section{Analyzing the relationship between roles and performance}

One of the objectives of this study was to explore the relationship between the middle managers' strategic role in the context of corporate entrepreneurship and performance. We use the canonical loadings of the independent variables to provide a possible interpretation of this relationship.

The role of middle managers as architects, i.e. in implementing in the context of organizational rejuvenation, is the dimension that contributes most to performance. With a canonical loading of .86, this dimension contributes about $76.21 \%$ (Figure 1) to the explained variance. The positive sign suggests that implementing strategies of organizational rejuvenation has a positive influence on performance. In other words, it suggests that providing the appropriate playground for employees to act entrepreneurial by shaping structure and process as well as introducing new services within the business unit will have a positive impact on performance viewed as a multidimensional construct.

Middle managers' roles in synthesizing (as leaders) and facilitating (as brokers) appear to have a moderate impact on performance. Their canonical loadings are $.30(9.27 \%$ contribution to the explained variance) and .34 (14.27\%), respectively. As one would expect, both variables have a positive effect on performance. Middle managers as leaders contribute positively to various dimensions of performance through their role in improving organizational arrangements by encouraging and sustaining employees' initiative. In their role as brokers, middle managers enhance performance through their contribution to organizational learning by using the flow of information available from their interactions with customers, employees and other managers.

Finally, the canonical results point to no association between middle managers' role as businessmen, i.e. the implementation of business-oriented strategies as part of organizational regeneration, and our multidimensional measure of performance. The canonical loading of only .07 is below the critical value of .30 .

In conclusion, middle managers' roles as architects, leaders and brokers are positively associated with a measure of performance that includes financial aspects as well as customers' and employees' concerns. Especially in their role as architects, i.e. by shaping the processes and structures that enable entrepreneurial initiatives to flourish, middle managers contribute to various dimensions of performance. It is interesting also that middle managers' role as businessmen, i.e. implementing strategies to regenerate business, is not associated with multiple dimensions of performance. Translating these findings into the language of existing terminology, our findings suggest that facilitating and implementing in the context of organizational rejuvenation, as well as synthesizing in the context of sustained regeneration, are positively associated with multiple dimensions of performance. Implementing in the context of regeneration appears not to have relevant consequences for multidimensional aspects of performance. 


\section{Conclusion}

The main objective of this study was to explore (1) the nature of the middle managers' strategic role in the context of CE seen as a combination of sustained regeneration and organizational regeneration, and (2) the link between middle managers' strategic role and performance. With the entrepreneurial initiative undertaken by ABN Amro bank at the end of the 1990s as our empirical setting, we first use the middle managers' entrepreneurial activities to provide a possible conceptualization of their strategic role in the context of CE. Our findings indicate that middle managers' strategic roles can be decomposed along four reliable and stable dimensions, which are consistent with those suggested in the literature. Their role as leaders and businessmen corresponds to synthesizing and implementing in the context of sustained regeneration; and their role as brokers and architects reflects facilitating and implementing in the context of organizational rejuvenation (Floyd and Woolridge, 1992, Dess, 2003). We then use this conceptualization to explore the relationship between strategic role and performance. We adopt a stakeholder approach and propose a performance measure that uses financial performance, customer satisfaction and employee satisfaction as its underlying dimensions. To analyze the strategic role-performance relationship, we employ canonical correlation analysis - a useful and powerful technique for exploring relationships among multidimensional variables. Our findings point to the importance of middle managers' role as architects, i.e. implementing in the context of organizational rejuvenation, and a performance instrument that considers the objectives of multiple stakeholders. The findings furthermore suggest that the middle managers' roles as leaders and brokers have a less relevant impact on performance. Overall, the canonical correlation results further corroborate that a stakeholder approach to assess performance is relevant.

Our study contributes to the understanding of the strategic role of middle managers in the context of CE by empirically identifying and documenting four roles and linking them to performance. This study also represents an important step toward understanding performance as a multidimensional concept that takes into account the expectations of different stakeholders of a firm. Our study further presents one possible way of integrating $\mathrm{CE}$ and strategic management research. While the importance of bringing together these fields has been pointed out by several researchers (Guth and Ginsberg, 1990; Zahra, 1991), little empirical research has been carried out in this area. Our study contributes in this direction by integrating work on modes of $\mathrm{CE}$ and strategic roles of middle managers.

There are several limitations to our findings. While the dimensions underlying middle managers' strategic role are robust and valid, there is a need to assess how general our findings are. This can be done, for example, by performing a similar empirical investigation for other corporations that have initiated $\mathrm{CE}$ initiatives in the context of sustained regeneration and organization rejuvenation. The use of a period of only three years to draw our conclusions may be too short a time horizon to evaluate the impact of the CE initiative on customer and employee satisfaction as well as financial results. Further, although our canonical correlation results point to a significant relationship, this relationship turns out to be weak. Yet this result is not surprising, as many studies concerned with the analysis of performance report similar conclusions. Finally, canonical correlation analysis also precludes an assessment of causal relationships. However, it is important to note that this study is an exploratory endeavor. Additional research to refine both the conceptualization of middle managers' strategic roles in the context of $\mathrm{CE}$ and their relationship with performance is needed to systematically build theory. Nevertheless, this study represents an attempt to push forward an existing line of research and provide a basis for further analysis. 
To conclude, this study has meaningful managerial implications for the growing number of companies that initiate CE programs. For example, the strategic roles identified can be used to determine priorities in the activities middle managers should engage in while a company is embarking on an entrepreneurial journey. Our study suggests further that, while financial performance is an essential objective of any $\mathrm{CE}$ initiative, it is becoming increasingly important to have satisfied employees and customers. Finally, our findings imply that encouraging middle managers in their role as architects, i.e. their role in implementing structures and processes that foster entrepreneurial initiative within existing organizations, is fruitful for achieving and integrating the objectives of shareholders, customers and employees.

\section{References}

Altman, E.I. 1971. Corporate Bankruptcy in America, Lexington, MA: Lexington Books.

Armor, D.J. 1974. Theta reliability and factor scaling. H.L. Costner (ed.), Sociological Methodology 1973-1974, Jossey-Bass, San Francisco, CA; 17-50.

Atkinson, A.A. and Waterhouse, J.H. 1997. A Stakeholder Approach to Strategic Performance Measurement. Sloan Management Review, 38: 25-38.

Bagozzi, R.P. and Phillips, L.W. 1982. Representing and testing organizational theories: a holistic construal. Administrative Science Quarterly, 17: 459- 489.

Bartlett, C.A. and Ghoshal, S. 1989. Managing Across Borders: The Transnational Solution. Boston, Harvard Business School Press.

Bower, J.L. 1970. Managing the Resource Allocation Process. Harvard Business School, Cambridge, MA.

Brancato, C.K. 1995. New Corporate Performance Measures, New York: The Conference Board.

Bryant, F.B. and Yarnold, P.R. 1995. Principal components analysis and exploratory and confirmatory factor analysis. Grimm, L.G. and Yarnold, P.R. Reading and understanding multivariate analysis. American Psychological Association Books.

Burgelman, R.A. 1983. Corporate entrepreneurship and strategic management: insights from a process study. Management Science 29(12): 1349-1364.

Burgelman, R.A. 1985. Managing the New Venture Division: Research Findings and Implications for Strategic Management. Strategic Management Journal 6(1): 39-55.

Chakravarthy, B.S. 1986. Measuring Strategic Performance. Strategic Management Journal 7: 328-339.

Child, J. 2001. Managerial and organizational factors associated with company performancepart I. The Journal of Management Studies.175-189.

Covin, J.G. and Miles, M.P. 1999. Corporate entrepreneurship and the pursuit of competitive advantage. Entrepreneurship Theory and Practice 23(3): 47-63.

Dess, G.G, Ireland, R.D., Zahra, S.A., Floyd, S.W., Janney, J.J. and Lane, P.J. 2003. Emerging issues in corporate entrepreneurship. Journal of Management 29(3): 351379.

Eccles, R.G. 1991. The Performance Measurement Manifesto. Harvard Business Review 69(1): 131-137.

Faulhaber, G.R. 1995. Banking markets: Productivity, risk and customer satisfaction. Wharton Financial Institutions Center, No. 95-14.

Flier, B., van den Bosch, F.A.J. and Volberda, H.W. 2003. Co-evolution in strategic renewal behaviour of British, Dutch and French financial incumbents: Interaction of environmental selection, institutional effects and managerial intentionality. Journal of Management Studies, 40(8): 2163-2187. 
Floyd, S.W and Lane, P.J. 2000. Strategizing throughout the organization: Managing role conflict in strategic renewal. Academy of Management Review 25(1): 154-177.

Floyd, S.W. and Woolridge, B. 1992. Middle management involvement in strategy and its association with strategic type: A research note. Strategic Management Journal 13: 153-167.

Floyd, S.W. and Woolridge, B. 1996. The strategic Middle Manager: How to create and sustain competitive advantage, Jossey-Bass Publishers, San Francisco.

Floyd, S.W. and Woolridge, B. 1997. Middle management's strategic influence and organizational performance. Journal of Management Studies 34(3): 465-485.

Fornell, C., Johnson, M.D., Anderson, C.J. and Bryant, B.E. 1996. The American customer satisfaction index: nature, purpose, and findings. Journal of Marketing 60: 7-18.

Fraser, D.R. Phillips, W. and Rose, P.S. 1974. A Canonical Analysis of Bank Performance. Journal of Financial and Quantitative Analysis 9: 287-295.

Frei, F.X., Kalakota, R., Leone, A.J. and Marx, L.M. 1999. Process variation as a determinant of bank performance: Evidence from the retail banking study. Management Science 45(9): 1210-1220.

Freeman, E.R. 1984. Strategic Management: A Stakeholders Approach, Boston: Pitman Publishing.

Grinyer, P.H., McKiernan, P. and Yasai-Ardekani, M. 1988. Market, Organizational and Managerial Correlates of Economic Performance in the U.K. Electrical.... Strategic Management Journal 9(4): 297-329.

Guth, W. and Ginsberg, A. 1990. Guest editor's introduction: Corporate entrepreneurship. Strategic Management Journal 11 (Summer Special Issue): 5-15.

Heskett, J.L., Jones, T.O., Loveman, G.W., Sasser, W.E. and Schlesinger, L.A. 1994. Putting the service-profit chain to work. Harvard Business Review; 164-174.

Kanter, R.M. 1982. The middle manager as innovator. Harvard Business Review 60(4): 95106.

Kaplan, R.S. and Norton, D.P. 1996. The Balanced Scorecard, Boston: Harvard Business School Press.

Kim, W.C. and Mauborgone, R. 1999. Creating new market space. Harvard Business Review 77(1): 83-93.

Kotler, P. 1991. Marketing and the death of the salesman. Harvard Business Review 69(2): 190-192.

Levine, M.S. 1997. Canonical analysis and factor comparison. Thousand Oaks, CA: Sage Publications, Quantitative Applications in the Social Sciences Series 6.

Mahmood, M.A. and Mann, G.J. 1993. Measuring the Organizational Impact of Information Technology Investment: An Exploratory Study. Journal of Management Information Systems 10(1): 97-122.

McGuire, J. and Schneeweis, T. 1983. An analysis of alternate measures of strategic performance. Paper presented at the $3^{\text {rd }}$ Annual conference of the Strategic Management Society, Paris.

Meredith, W. 1964. Canonical correlations with fallible data. Psychometrika 29: 55-65.

Nahapiet, J. and Ghoshal, S. 1998. Social capital, intellectual capital, and the organizational advantage. Academy of Management Review, 23(5): 242-266.

Rappaport, A. 1981. Selecting strategies that create shareholder value. Harvard Business Review; 139-149.

Sathe, V. 1989. Fostering entrepreneurship in a large diversified firm. Organizational Dynamics, 18: 20-32.

Schollhammer, H. 1982. Internal corporate entrepreneurship. In C.A. Kent, D.L. Sexton, and K.H. Vesper, eds., Encyclopedia of Entrepreneurship. Englewood Cliffs, NJ: Prentice Hall; 209-223. 
Sharma, P. and Chrisman, J.J. 1999. Toward a reconciliation of the definitional issues in the field of corporate entrepreneurship. Entrepreneurship Theory and Practice 23(3): 11-27.

Stewart, D. and Love, W. 1968. A general canonical correlation index. Psychological Bulletin 70: $160-163$.

Thorndike, R.M. and Weiss, D.J. 1973. A study of the stability of canonical correlations and canonical components. Educational and Psychological Measurement 33: 123-134.

Venkatraman, N. and Ramanujam, V. 1986. Measurement of business performance in strategy research: A comparison of approaches. Academy of Management Review 11(4): 801814.

Volberda, H.W., Baden-Fuller, C. and van den Bosch, F.A.J. (2001). Mastering Strategic Renewal. Long Range Planning, 34: 159-178.

White, G., Sondhi, A. and Fried, D. 1997. The Analysis and Use of Financial Statements. John Wiley and Sons, New York.

Wiklund, J. 1999. The sustainability of the entrepreneurial orientation-performance relationship. Entrepreneurship Theory and Practice, 24(1): 37-47.

Vozikis, G.S., Bruton, G.D., Prasad, D. and Merikas, A.A. (1999). Linking corporate entrepreneurship to financial theory through additional value creation. Entrepreneurship Theory and Practice, 24(2): 33-43.

Wood, R.D. and LaForge, R.L. 1979. The impact of comprehensive planning on financial performance. Academy of Management Journal 22(3): 516-526.

Zahra, S.A. 1991. Predictors and financial outcomes of corporate entrepreneurship: an exploratory study. Journal of Business Venturing 6: 259-286.

Zahra, S.A. and Covin, J.G., 1995. Contextual influences on the corporate entrepreneurship-firm performance relationship: a longitudinal analysis. Journal of Business Venturing 10 (1): 43-58.

Zahra, S.A., Nielsen, A.P. and Bogner, W.C. (1999). Corporate entrepreneurship, knowledge, and competence development. Entrepreneurship Theory and Practice, 23(3): 169-190. 


\section{Appendix 1}

\section{Questionnaire}

\section{Activities of an area (unit) manager}

Managers engage in a variety of activities. The following series of questions are set out to give me a well-rounded and realistic picture of the job of a rayon manager. It is important for me to understand the activities you did and did not undertake in your function as a rayon manager after the start of Vision 2000.

\section{Please indicate whether you engaged in the particular activities described below}

If you did not, please circle 1 . If you did engage in the activity, please specify from 2 - 7 the level of effort you put into it.
to no exten
$2 \quad 3$
4
5
6
to a great extent

I understand that in managerial reality it is rarely (seldom) possible to perform all activities one would like to because of time and organizational restrictions. Please bear in mind that I am interested in a realistic picture of YOUR work as a rayon manager. Therefore, it is important that you indicate your "actual" behavior and NOT what you consider to be an "ideal" pattern if there were no constraints (restrictions). To what extent did you carry out the following activities
in your job as rayon manager over the last few years?

1. Exchanging ideas with other rayon managers on commercial activities

2. Changing procedures to facilitate client contact within your rayon

3. Promoting entrepreneurial behavior of employees with initiatives that went beyond the ones suggested by head office

4. Regularly discussing ideas and problems with colleagues at the regional office

5. Developing tailor-made bonus systems to honor commercial efforts of employees within your rayon

6. Encouraging employees to come up with their own solutions to problems

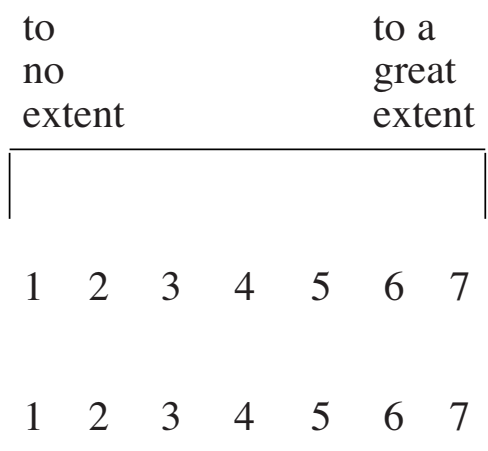

$\begin{array}{lllllll}1 & 2 & 3 & 4 & 5 & 6 & 7\end{array}$

$\begin{array}{lllllll}1 & 2 & 3 & 4 & 5 & 6 & 7\end{array}$

$\begin{array}{lllllll}1 & 2 & 3 & 4 & 5 & 6 & 7\end{array}$

$\begin{array}{lllllll}1 & 2 & 3 & 4 & 5 & 6 & 7\end{array}$ 
Appendix 1 (continued)

7. Changing the focus on specific client segments

8. Involving employees outside the management team in decision-making processes of the rayon

$\begin{array}{lllllll}1 & 2 & 3 & 4 & 5 & 6 & 7 \\ 1 & 2 & 3 & 4 & 5 & 6 & 7 \\ 1 & 2 & 3 & 4 & 5 & 6 & 7 \\ 1 & 2 & 3 & 4 & 5 & 6 & 7 \\ 1 & 2 & 3 & 4 & 5 & 6 & 7 \\ 1 & 2 & 3 & 4 & 5 & 6 & 7 \\ 1 & 2 & 3 & 4 & 5 & 6 & 7\end{array}$

13. Reorganizing the customer complaints process

14. Introducing new service concepts beyond the ones provided by head office (e.g. top-retail, entrepreneur-desk)

$\begin{array}{lllllll}1 & 2 & 3 & 4 & 5 & 6 & 7\end{array}$

15. Holding feedback or coaching talks with employees on a regular basis

$\begin{array}{lllllll}1 & 2 & 3 & 4 & 5 & 6 & 7\end{array}$

16. Organizing events for customers and/or inter mediaries

$\begin{array}{lllllll}1 & 2 & 3 & 4 & 5 & 6 & 7\end{array}$

17. Expanding the amount of management information available to employees in the rayon

$\begin{array}{lllllll}1 & 2 & 3 & 4 & 5 & 6 & 7\end{array}$

18. Actively investigating new market opportunities within the rayon

$\begin{array}{lllllll}1 & 2 & 3 & 4 & 5 & 6 & 7\end{array}$

19. Submitting ideas developed in your rayon to the product development group at head office

$\begin{array}{lllllll}1 & 2 & 3 & 4 & 5 & 6 & 7\end{array}$

20. Developing new supporting systems, e.g. for internal reporting or evaluation in your rayon

$\begin{array}{lllllll}1 & 2 & 3 & 4 & 5 & 6 & 7\end{array}$

21. Changing the spectrum (range) of services offered in the branches

$\begin{array}{lllllll}1 & 2 & 3 & 4 & 5 & 6 & 7\end{array}$

22. Encouraging your employees to develop new ideas on how to do business 
Appendix 2

\section{Factor analysis constructs and their underlying items}

\section{Strategic role 1 - Leader}

- Encouraging employees to come up with their own solutions to problems

- Involving employees outside the management team in decision-making processes of the rayon

- $\quad$ Praising employees for doing their job well

\section{Strategic role 2 - Broker}

- Exchanging ideas with other rayon managers on commercial activities

- Regularly discussing ideas and problems with colleagues at the regional office

- Exchanging ideas with other rayon managers on how to motivate employees

- $\quad$ Encouraging other rayon managers to adopt (take up) ideas developed in your rayon

\section{Strategic role 3 - Businessman}

- Initiating marketing campaigns in addition to the ones promoted by head office

- Organizing events for customers and/or intermediaries

- Actively investigating new market opportunities within the rayon

- Encouraging your employees to develop new ideas on how to do business

\section{Strategic role 4 - Architect}

- $\quad$ Changing procedures to facilitate client contact within your rayon

- Promoting entrepreneurial behavior of employees with initiatives that went beyond the ones suggested by head office

- Developing tailor-made bonus systems to honor commercial efforts of employees within your rayon

- Reorganizing the customer complaints process

- Introducing new service concepts beyond the ones provided by head office (e.g. top-retail, entrepreneur-desk)

\section{Strategic role 5}

- Holding feedback or coaching talks with employees on a regular basis

- Expanding the amount of management information available to employees in the rayon

- Developing new supporting systems, e.g. for internal reporting or evaluation in your rayon 


\section{Appendix 2 (continued)}

\section{Strategic role 6}

- $\quad$ Changing the focus on specific client segments

- $\quad$ Submitting ideas developed in your rayon to the product development group at head office

- Changing the spectrum (range) of services offered in the branches 